\title{
Selfie : Mediatisasi Tubuh Perempuan Berjilbab Seksi Dalam Instagram
}

\author{
Juliana Kurniawati \\ Program Studi Ilmu Komunikasi, Universitas Muhammadiyah Bengkulu, Jl. H. Adam Malik No. 17, Bengkulu, 38211 \\ E-mail: juliana@umb.ac.id
}

\begin{abstract}
Aktivitas Selfie yang dilakukan oleh perempuan berjilbab merupakan ranah yang menarik untuk dikaji. Perempuan berjilbab dengan tubuhnya mengusung seperangkat aturan dan norma-norma agama yang menghendaki untuk dipatuhi. Sebagaimana layaknya perempuan yang aktif berjejaring sosial di Instagram maka aksi foto selfie menjadi keniscayaan demikian pula bagi perempuan berjilbab. Tulisan ini mengkaji mengenai praktek mediatisasi tubuh perempuan berjilbab seksi melalui foto selfie dalam Instagram. Pertanyaan yang diajukan dalam tulisan ini adalah "bagaimana praktek mediatisasi dalam foto selfie perempuan berjilbab yang diunggah dalam Instagram dengan hashtag/tagar \#jilboob dan \#hijaboob?" Untuk menjawab pertanyaan tersebut maka akan dilakukan kajian terhadap akun-akun yang terkait dengan \#jilboob dan \#hijaboob. Kajian ini menggunakan pendekatan teori mediatisasi dari Stig Hjarvard. Hasil yang didapatkan terjadi perubahan dalam cara perempuan menunjukkan citra dirinya melalui logika media. Praktek mediatisasi perempuan berjilbab seksi sebagai sebuah fenomena global yang difasilitasi oleh media. Penggunaan jilbab tidak terkait dengan simbol agama hanya sebagai aksesories belaka.
\end{abstract}

Keywords - : selfie; mediatisasi; perempuan berjilbab; seksi.

\section{PENDAHULUAN}

Selfie (self-potrait) atau dalam Bahasa Indonesia disebut sebagai swafoto merupakan salah satu fenomena yang populer terutama di kalangan pengguna sosial media. Kepopuleran fenomena selfie ini tidak lain karena selfie semakin marak dilakukan oleh masyarakat kemudian menjadi trend. Aksi selfie ini digemari oleh berbagai kalangan mulai remaja sampai orang dewasa, dari masyarakat hingga tokoh masyarakat sampai pemimpin negara. Aksi swafoto yang dimulai pada abad ke-19 ini, semakin populer dengan dukungan teknologi fotografi yang semakin canggih.

We are already experiencing the cultural effects of the digital revolution that is underway (Cross dalam Nasrullah, 2016:xi). Revolusi teknologi dan media baru (new media) terhubung dalam segenap aspek kehidupan manusia. Media sosial sebagai bagian integral dari media baru serta merta turut mengambil bagian dalam revolusi ini. Kita melakukan komunikasi antar manusia melalui berbagai media, media sosial hanya salah satu contoh media komunikasi. Komunikasi yang kita lakukan melalui media disebut dengan mediasi. Segala sesuatu yang kita komunikasikan merupakan suatu hal yang termediasi (mediated).

Kehidupan manusia yang literat di era teknologi informasi tidak lengkap tanpa gadget canggih. Gadget berupa smartphone yang awalnya hanya untuk komunikasi jarak jauh baik lewat suara maupun teks kini dilengkapi berbagai macam fitur dengan bermacam fungsi. Fitur tersebut diantaranya fitur untuk foto selfie dengan bermacam aplikasi yang dapat diunduh dari playstore. Hasil foto selfie ini akan diseleksi, dipilih mana yang terbaik menurut pengguna kemudian diunggah ke akun social media atau dijadikan foto profile pada akun Twitter, Blackberry Messager, Line dan akun media yang lain terutama instagram.

Instagram merupakan media sosial yang dirilis pertama kali pada 6 Oktober 2010. Instagram merupakan aplikasi berbagi foto yang memungkinkan pengguna untuk mengambil foto dan menerapkan filter digital dalam foto yang telah diambil, kemudian diunggah. Melalui instagram, orang-orang dapat berbagi berbagai hal mengenai momen pribadi mereka dalam bentuk foto dan video berdurasi pendek yang dapat disertai caption dan hashtag kepada akun lain yang dituju. Status pengguna berupa foto yang mereka unggah ke dalam akun Instagram dapat dengan mudah dilihat dan diakses oleh orang yang terhubung. Trend berbagi foto pada Instagram memiliki fungsi lain, yaitu tidak hanya sekedar berbagi tetapi juga menjadi ajang eksistensi diri dengan banyak bermunculan akun-akun Instagram yang populer berkat foto-foto yang diunggahnya, sehingga memiliki ribuan bahkan ratusan ribu pengikut akun.

Instagram memiliki pengguna terbesar kedua di Indonesia setelah Facebook. Pengguna Instagram Indonesia didominasi oleh perempuan dengan persentase yang mencapai 63 persen, sementara pengguna laki-laki hanya sebanyak 37 persen. Data tersebut merupakan hasil studi terhadap pengguna Instagram di Indonesia yang dilakukan oleh TNS Indonesia pada awal tahun 2016. Temuan lain yang dipaparkan adalah mengenai mayoritas pengguna Instagram yang memiliki latar belakang pendidikan tinggi (well educated) dengan angka sebesar 69 persen bergelar sarjana (http://m.beritasatu.com/iptek/341956-pengguna-instagram-diindonesia-mayoritas-perempuan.html diakses pada 29 Mei 2017).

Berdasarkan hasil studi tersebut, perempuanlah yang lebih aktif melalui media sosial dalam menampilkan citra dirinya kepada khayalaknya. Citra diri yang ingin dibangun ini berbeda antara perempuan yang satu dengan perempuan yang lain, 
tergantung pada berbagai aspek yang melatarbelakangi konstruksi diri yang ingin ditampilkan. Diri perempuan yang ditampilkan pada foto terkait dengan tubuh. Tubuh perempuan dari ujung rambut sampai ujung kaki didandani sedemikian rupa dengan aksesoris yang menarik untuk membedakan diri perempuan satu dengan perempuan lainnya.

Ketika kita akan mengunggah foto selfie, sudah pasti kita akan melakukan seleksi. Kita akan mengunggah foto yang menurut kita paling bagus dalam menampilkan citra diri kita dihadapan khalayak dunia maya. Dalam dunia maya identitas diri seakan mencair, kita bisa menjadi siapa saja sesuka kita, karena dunia maya seakan identitas kedua kita. Termasuk dalam aktivitas foto diri, kita dapat menjadi siapa saja dengan menggunakan kostum yang kita inginkan. Dunia maya seakan menjadi panggung dramaturgi, dimana semua orang dapat mengkonstruksi dirinya termasuk dengan perempuan berjilbab.

Semakin mudahnya kita untuk membentuk identitas melalui media sosial menjadi semacam arena baru bagi perempuan berjilbab untuk menjadi self yang dipilihnya dalam upaya melakukan eksistensi. Masyarakat mengkonstruksi perempuan berjilbab sebagai perempuan yang mengusung nilai modesty, nilai kesopanan dan nilai kesederhanaan dalam menampilkan citra dirinya sebagaimana aturan dalam agama. Namun jamak kita temui foto selfie perempuan berjilbab yang berlawanan dengan nilai-nilai tersebut di media sosial. Kesan glamour nan seksi dalam mendandani tubuh justru yang ditampilkan oleh beberapa perempuan berjilbab dalam foto selfie mereka.

Foto sebagai teks pada akun media sosial merupakan salah satu cara kita melakukan komunikasi dengan orang lain. Mediasi yang dilakukan melalui foto terkait pertukaran pesan melalui media (Instagram) tanpa berhubungan dengan otonomi media serta tidak melihat pengaruhnya. Mediasi yang terjadi terfokus pada aspek teknis mengenai proses berlangsungnya komunikasi itu sendiri. Mengenai bagaimana penerima dapat memahami simbol (dalam hal ini foto) yang dikomunikasikan oleh media tanpa melihat pengaruhnya. Media berperan dalam membangun makna. Mediasi bukan sekedar menyampaikan pesan, melainkan pesan dalam konteks mediasi sangat penting karena ada konteks kultural didalamnya. Sebagaimana konsep mediatisasi menurut Stig Hjarvard pada tahapan institusi. Logika dibelakang mediatisasi adalah ada teknologi media. Mediatisasi terjadi karena otoritas media yang kuat (Mahanani ; 2016).

Ketertarikan penulis untuk mengkaji mengenai mediatisasi perempuan berjilbab seksi dalam Instagram diawali ketika penulis melihat akun yang berisi kumpulan foto selfie perempuan berjilbab yang mengenakan pakaian ketat nan seksi. Admin akun tersebut memilih nama yang mengusung simbol agama semacam akun@jilbabfanspage, @jilbab_alim, @jilbab_cantik23, @jilbabootd namun foto-foto yang ditampilkan justru berlawanan dengan nama akun yang dipilih. Penulis menelusuri akun sejenis, pada akhirnya menemukan hashtag \#jilboob dan \#hijabob.

Berdasarkan hasil temuan awal tersebut akhirnya penulis menelusuri beberapa akun di Instagram. Penelusuran menghasilkan beberapa akun yang cukup menarik yaitu @jilbabfanspage, @jilbabcute, @jilbabhunter, @jilbabootd, @hijaboobs_, @hijab_seksi100, @jilbabhots, @hijaboobpedia, @jilboobs_malaysia, @jilboob_exposure, @jilbooobs_hot, @jilboob_id, @jilboobsjogja,@jilboobs_strip, @ modelhijabsexy, @jilboob_jilbab, @jilbaboober, @cewek_jilbab_hijab_jilboob, @jilboobsfans, @jilbooobs_, @jilbab_cantik23, @jilbab_alim, @jilbabseksi99. Akun-akun tersebut berisi kumpulan foto perempuan berjilbab. Namun akun ini berbeda dengan akun-akun yang berisi kumpulan foto berjilbab lainnya, akun ini menampilkan kumpulan foto perempuan berjilbab dengan pose dan pakaian seksi walau mengenakan penutup kepala. Pertanyaan yang diajukan dalam tulisan ini adalah "bagaimana praktek mediatisasi foto selfie perempuan berjilbab seksi dalam Instagram?" Untuk menjawab pertanyaan tersebut maka akan dilakukan kajian terhadap foto-foto selfie perempuan berjilbab pada beberapa akun di Instagram.

\section{DISKUSI}

Selfie, sebagai salah satu trend kekinian yang telah menjadi budaya dan dapat diterima oleh masyarakat. Dimanapun kita berada dan kapanpun, kita dapat dengan mudah melihat aktivitas selfie tersebut. Selfies are suddenly ubiquitous (Senft\&Baym, 2015:1589). Selfie adalah salah satu contoh praktek mediatisasi. Mediatisasi adalah proses yang on going atau terus menerus terjadi. Ketika masyarakat sangat tunduk dan tergantung pada media dan logika media, maka media menjadi independen. Mediatisasi telah merubah cara orang berelasi. Sebagaimana pendapat Couldry dan Hepp dalam Conceptualizing Mediatization : Contexts, Traditions, Arguments sebagai berikut "mediatization is a concept used to analyze critically the interrelation between changes in media and communications on the one hand, and changes in culture and society on the other" (2013:6).

Praktik mediatisasi waktunya inklusif yaitu menyesuaikan dengan logika media antara lain komersial, institusional, dan teknologi. Menurut Stig Hjarvard, mediatisasi adalah proses di mana masyarakat menjadi semakin tunduk dan tergantung pada media dan logika media. Sementara logika media (media logic) mengacu pada proses dan asumsi dalam konstruksi pesan-pesan melalui medium tertentu, khususnya terobosan teknologi komunikasi (Mahanani;2016).

Aksi foto selfie bukanlah fenomena baru, demikian pula perempuan berjilbab yang mengenakan pakaian seksi atau biasa dikenal dengan istilah jilboob. Dalam keseharian kita dapat kita lihat dua fenomena tersebut. Namun aksi foto selfie seksi yang diunggah pada kumpulan foto di akun instagram ini adalah sebuah fenomena baru. Logika media dalam hal ini adalah logika Instagram sebagai institusi berkelindan dengan logika perempuan yang mengirimkan foto pada akun yang berisi foto perempuan berjilbab seksi. Logika media sebagaimana disebutkan oleh Couldry dan Hepp "this media logic on the one hand, takes up non mediatized form of representation, on the other hand, non media actors have to conform to this media logic, if they want to be represented in the media or if they want to act sucessfully in a media culture and media society" (2013:5).

\section{III.PRAKTEK MEDIATISASI PEREMPUAN BERJILBAB SEKSI MELALUI FOTO SELFIE}


Website : http://sosial.unmermadiun.ac.id/index.php/sosial

Aksi foto Selfie adalah salah satu cara dimana perempuan bebas menjadi diri sendiri dan perempuan pun memiliki kekuasaan untuk mengatur bagaimana tubuh mereka ingin dilihat oleh publik. Diri yang ditampilkan terkait dengan identitas yang ingin dikonstruksikan. Foto selfie perempuan berjilbab yang menampakkan keanggunan diri dalam berpakaian dan berpose pun marak kita temui di berbagai akun media sosial. Namun foto selfie perempuan berhijab dengan pose dan pakaian seksi menjadi sesuatu yang berbeda. Semacam ingin membebaskan diri dari kungkungan tradisi dan aturan agama yang dipatuhi namun menjadi ambivalen ketika foto selfie tersebut justru menjadi obyek tatapan terutama tatapan laki-laki, menjadi obyek fantasi seksual, desire serta pleasure.

Media sosial berjalan dengan logikanya sendiri dimana apabila foto diri kita telah terpampang disitu maka sudah menjadi hak publik untuk menatapnya bahkan siapapun bisa menjadi shape shifting authorship. Kita tidak dapat mengambil jarak dengan fenomena media karena kita hidup dalam masyarakat media. Setiap orang memperlakukan media berbeda-beda sesuai tujuan dan kepentingannya. Demikian pula halnya dengan logika media yang berbeda-beda pula nalarnya. Banyak ragam akun Instagram yang berisi kumpulan foto perempuan berjilbab, berpakaian ketat dengan pose seksi. Berikut tampilan halaman awal beberapa akun yang berisi kumpulan foto perempuan berjilbab tersebut :

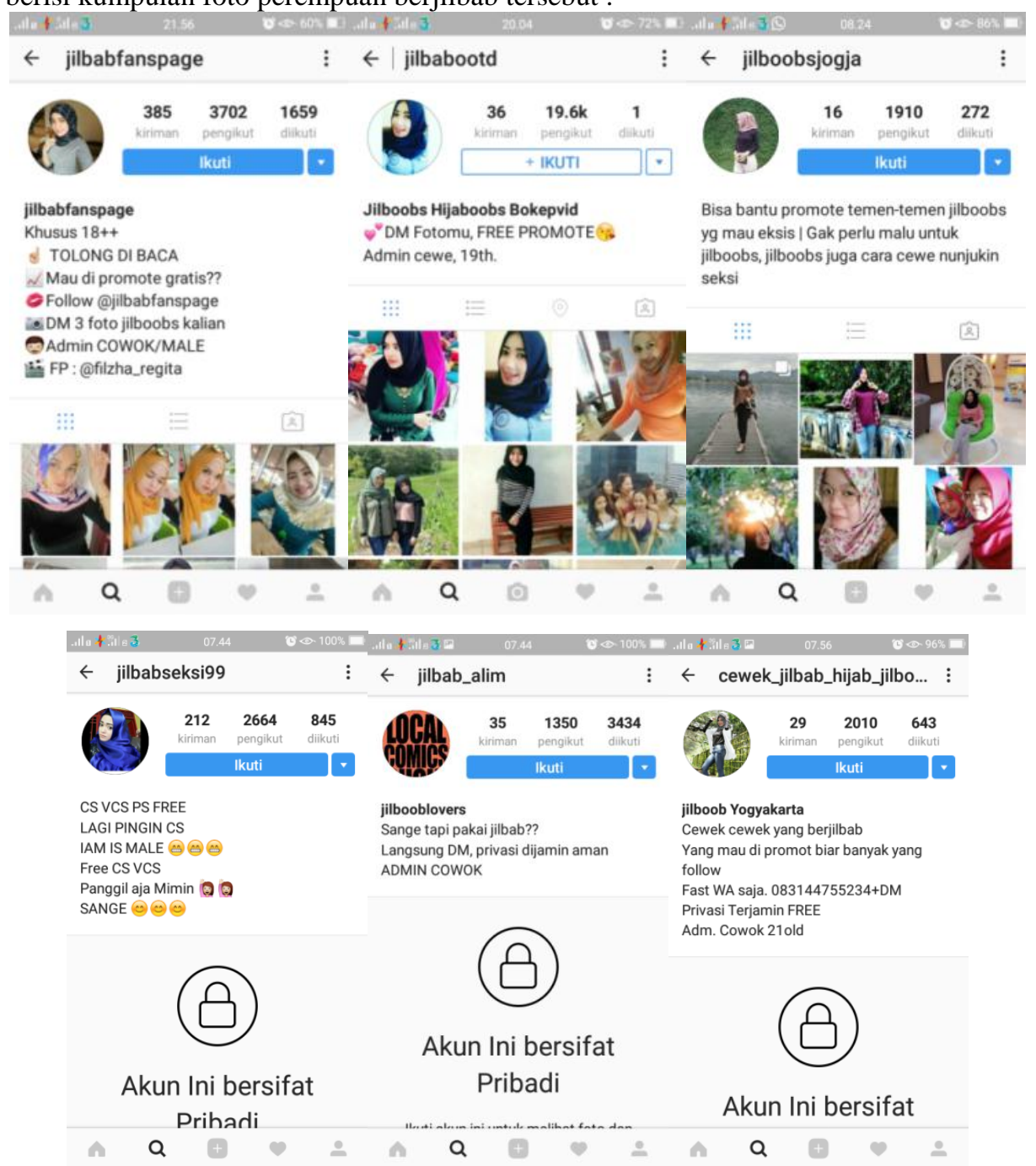


Website : http://sosial.unmermadiun.ac.id/index.php/sosial

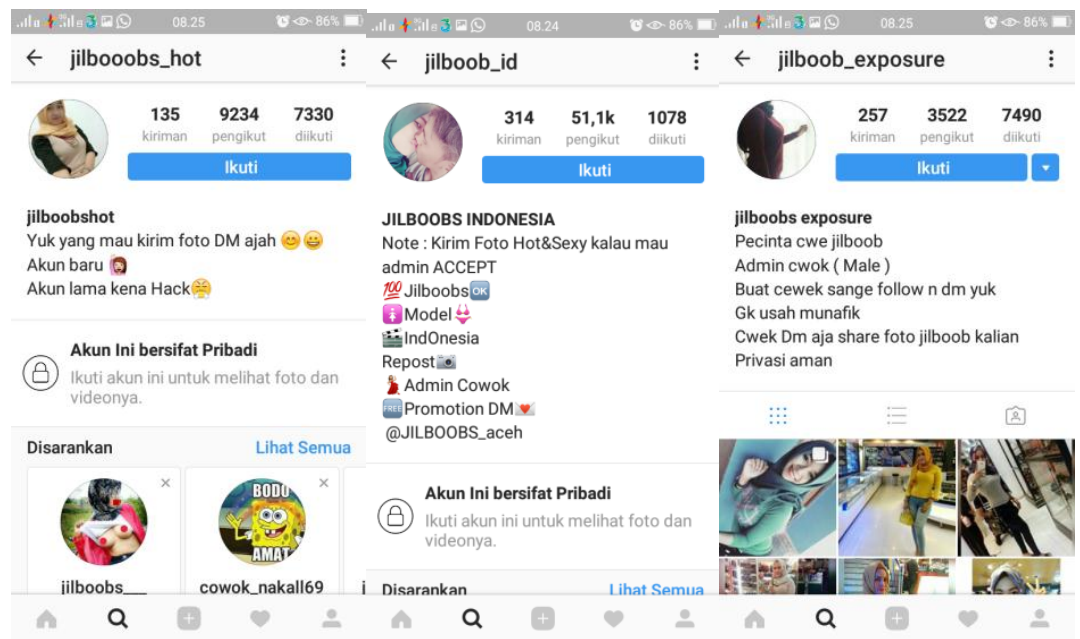

Fenomena jilboobs di Indonesia bukanlah hal yang baru. Jilboobs adalah kerudung yang dikenakan tidak menutupi bagian payudara, sementara pakaian yang dikenakan ketat mengekspose wilayah dada. Perempuan yang mengenakan kerudung namun berpakaian ketat dapat kita temui dalam keseharian kita. Namun menjadi sesuatu yang menarik manakala foto selfie tersebut muncul pada akun yang ditujukan untuk mengeksploitasi tubuh perempuan. Eksploitasi dengan alasan dipromosikan untuk mendapatkan follower pada akun pribadi si pemilik foto ini, sementara jelas sekali pengikut pada akun tersebut diatas mayoritas berjenis kelamin laki-laki. Pada tampilan awal halaman akun@jilbabfanspage dapat kita lihat kalimat "DM (Direct Message) tiga foto jilboobs kalian", dari sini terbaca bahwa perempuan yang diminta untuk mengirimkan 3 foto jilboobs kemudian admin yang memutuskan foto mana yang akan diunggah.

Admin pada akun yang menampilkan perempuan berjilbab seksi, berdasarkan hasil penelusuran, mayoritas berjenis kelamin laki-laki, hanya satu akun yaitu @jilbabootd yang memiliki admin perempuan. Fenomena ini sejalan dengan logika media dimana menempatkan perempuan sebagai obyek. Dalam hal ini perempuan yang juga memiliki hasrat untuk ditatap oleh lakilakilah yang secara sadar akan mengirimkan foto dirinya dalam pose seksi yang menggoda. Tujuan para perempuan ini mengirimkan fotonya untuk diseleksi admin tentu berbeda-beda. Perempuan yang mengirimkan foto selfie mengenakan jilbab ternyata dalam akun pribadinya tidak mengenakan jilbab, sebagai contoh dapat kita lihat pada screen shoot dibawah :

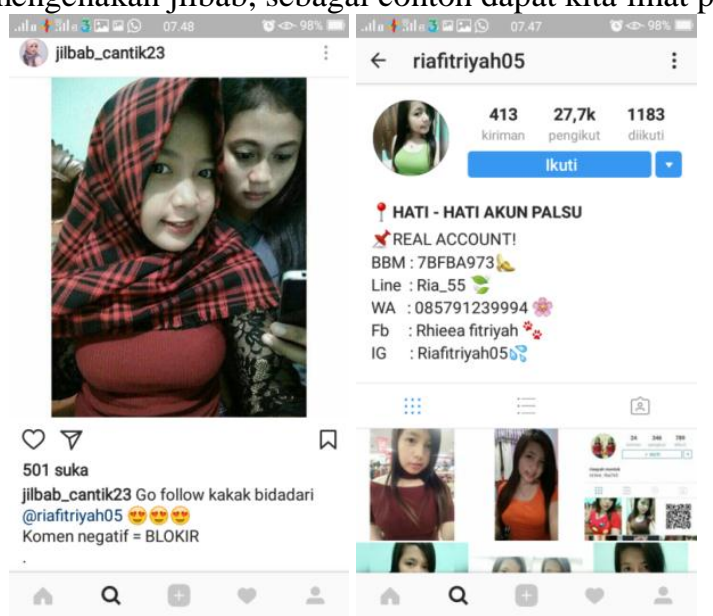

Ada pula sebaliknya dimana dapat kita lihat pada akun pribadi si pengirim foto selfie mengenakan jilbab berpakaian sopan namun justru berpose dan berdandan seksi untuk dikirimkan (DM) pada admin salah satu akun tersebut diatas. Dalam hal ini si pengirim foto selfie tersebut mengikuti aturan atau logika media dimana mengharuskan pengirim foto untuk mengenakan jilboob dengan foto selfie tubuh seksinya.

Hasil penelusuran menemukan dua jenis akun berdasarkan khalayak yang dapat melihat isi akun yaitu pertama akun yang terbuka dan kedua akun yang tertutup. Akun terbuka mengijinkan siapapun melihat unggahan foto, sementara akun tertutup sebaliknya apabila ingin melihat foto-foto yang terpampang pada akun tersebut harus menjadi pengikut. Dalam hal promosi terdapat dua jenis akun pula, pertama akun yang menuliskan identitas Ig (Instagram) si pemilik foto agar pengikut yang tertarik dengan pemilik foto tersebut menjadi pengikut, jenis kedua adalah akun yang hanya menampilkan foto saja tanpa menuliskan identitas Ig si pemilik foto. Berdasarkan sistem pembayaran promote foto juga terdapat dua jenis yaitu free promote dan paid promote. Hal yang menarik dari beberapa akun yang berisi kumpulan foto perempuan seksi terdapat pada akun@jilbooobs_hot dan akun@jilbabhots. Kedua akun ini pernah terkena hack serta banned kemudian mengganti namanya. Nama lama akun @jilbabhots adalah@jilbabhott. Sayang sekali tidak didapat informasi nama akun lama dari @jilbooobs_hot. 
Website : http://sosial.unmermadiun.ac.id/index.php/sosial

Berdasarkan hasil penelusuran terhadap akun-akun tersebut terdapat istilah-istilah yang digunakan sebagai bahasa berkomunikasi yaitu : CS (Chat Sex), PS (Phone Sex), VCS (Video Call Sex), BO (Booking Out), DM (Direct Message), Sange $(\mathrm{Sa}=$ sakaw, $\mathrm{Nge}=$ ngewe $=$ bersetubuh arti lainnya adalah bernafsu $)$. Istilah-istilah ini dapat kita temui pada kolom komentar dan halaman awal pada akun Instagram sebagai rules. Sebagaimana telah terkonstruksi dalam struktur masyarakat bahwa lakilaki wajar dan sah saja apabila memiliki nafsu terhadap lawan jenis yang diumbar melalui komentar terhadap foto seksi, namun perempuan sebagai pihak yang terepsi menjadi tidak wajar apabila memiliki nafsu bahkan sampai mengumbarnya melalui foto seksi terutama bagi perempuan berjilbab. Akun yang mengekspose tubuh perempuan berjilbab seksi ini seakan menjadi tempat bagi para perempuan untuk menjadi dirinya yang tidak dapat ditunjukkan dalam dunia offline. Kata-kata yang digunakan seperti "gak perlu malu untuk jilboobs, jilboobs juga cara cewek untuk menunjukkan seksi", "sange tapi pake jilbab? Langsung DM privasi dijamin aman" semacam ajakan bagi perempuan untuk menjadi "berbeda" di dunia online. Namun tentu saja ajakan ini berlaku hanya bagi perempuan yang merasa menjadi subyek yang terpanggil.

Kumpulan foto selfie perempuan berjilbab seksi yang dikoordinir oleh admin menjadi ajang pamer tubuh seksi di smartphone. Fenomena ini terjadi secara global tidak hanya di Indonesia. Perempuan berjilbab yang mengirimkan foto selfienya pada admin dalam posisi sadar bahwa ketika foto yang dikirimkannya di publish maka foto tersebut berada pada ranah publik dan menjadi obyek tatapan dan fantasi seksual terutama bagi laki-laki. Perempuan ini sadar dan mungkin justru bangga karena tersalurkan hasratnya mendapatkan banyak tanda love dan komentar pada foto seksinya.

Aktivitas berfoto selfie pada dasarnya bersifat pribadi, namun ketika foto selfie diri telah diunggah ke media sosial terutama Instagram maka foto tersebut telah menjadi milik public tidak lagi berada dalam ranah private, dengan segala konsekuensinya. Sebagai bentuk representasi diri, selfie mengungkapkan interaksi yang kompleks antara politik identitas, obyektifikasi dan estetika diri perempuan.

Dalam hal ini terjadi ambivalensi antara fungsi jilbab sebagai salah satu tanda kesalehan dengan hasrat perempuan yang ingin menampilkan tubuhnya secara seksi di media sosial. Dalam logika media terlepas benar dan salah, terlepas pengaruhnya terhadap masyarakat, fenomena yang terjadi menunjukkan bahwa perempuan berjilbab seksi telah dapat bernegosiasi antara logika diri dengan logika media.

\section{IV.KESIMPULAN}

1. Akun semacam @jilbabootd dan @jilbabfanspage sengaja dibuat untuk keperluan obyektifikasi foto selfie seksi perempuan berjilbab.

2. Jilbab yang dikenakan oleh perempuan pada akun ini hanya sebagai properti semata tidak menunjukkan identitas agama.

3. Mediatisasi telah merubah relasi antara diri perempuan dengan media.

4. Nama akun dengan identitas agama yang digunakan hanya menjadi pengalihan supaya tidak ditutup oleh pihak Instagram selaku institusi.

\section{DAFTAR PUSTAKA}

Antoni. 2005. Kamus Besar Bahasa Indonesia (edisi 3) . Departemen Pendidikan Nasional. Jakarta. Balai Pustaka

Couldry, Nick/Hepp, Andreas (2013): Conceptualising mediatization: Contexts, traditions, arguments. In: Communication Theory, 23 (3), pp. 191 -202, doi: $10.1111 /$ comt. 1201

Hjarvard, Stig. (2008). The Mediatization of Society: A Theory of The Media as Agents of Social and Cultural Change. Journal Nordicom Review 29 (2008) 2, pp. 105-134

Mahanani, Prima Ayu. Mediatisasi Pada Aktivitas Dakwah Perempuan Salafi. Jurnal Ri’Ayah Vol. 01, No. 02 Juli - Desember 2016

Senft, Theresa M. dan Baym, Nancy K., 2015, What Does the Selfie Say, International Journal of Communication 9 ,

http://lifestyle.kompas.com/read/2016/10/07/160357620/hasil.riset.pribadi.extrovert.dan.eksibisionis.penggemar.berat.selfie diakses pada 2 Juni 2017.

http://m.beritasatu.com/iptek/341956-pengguna-instagram-di-indonesia mayoritas-perempuan.html diakses pada 29 Mei 2017 